\title{
Fatal crashes in GCC countries: comparative analysis with EU countries for three decades
}

\author{
H. M. N. Al-Madani \\ Department of Civil Engineering and Architecture, \\ College of Engineering, University of Bahrain, Bahrain
}

\begin{abstract}
Traffic safety data for the Gulf Cooperation Council (GCC) countries, namely Saudi Arabia, Kuwait, Qatar, Oman, UAE and Bahrain, are analysed here and compared with EU countries. The comparison is based on data gathered for over three decades considering death frequencies and rates. The predicted values for the coming decade, based on best regression fits, are also analysed. The gathered data for the various GCC countries are probably presented for the first time in the literature. While the traffic fatalities in the GCC countries increased from 3,531 during 1980 to 9,685 deaths during 2011; those in 15 EU countries dropped from 59,879 deaths to 20,764 . It is expected that roadway deaths in both will reach 10,700 by the year 2021 . The fatality rates per population for the GCC countries as a whole were shown to be substantially higher than those in EU countries. While the rates for EU countries were shown to be around 13.5 deaths per 100,000 population during the $80 \mathrm{~s}$; those in the GCC countries were in the range of 22 to 27 . The current rates for the EU countries are around 5.5. Those in the GCC countries are around 23 deaths per 100,000 inhabitants. As per regressed models; EU fatality rates will continue dropping towards zero in about 10 years' time; those for GCC countries will stay in the range of 20 deaths per 100,000 population. There are many contributory factors leading to such high rates of traffic deaths in GCC countries. These include lack of measurable long term safety plans, inconsistent handling of traffic safety strategies, poor involvement of NGOs, poor coordination between various stakeholders, poor research involvement in the traffic safety crises and limited post accident rehabilitation centres.
\end{abstract}

Keywords: traffic safety, roadway deaths, fatality rates, GCC, EU. 


\section{Introduction}

Gulf Cooperation Council Countries consists of Saudi Arabia, Kuwait, Qatar, United Arab Emirates (UAE), Oman and Bahrain. The population of the six countries in total is around 41 million, as per 2011 data. The population growth is quite high (fig. 1) as compared with 15 and 27 European Council Countries. The population of 15 EU countries, consisting of Austria, Belgium, Denmark, Finland, France, Germany, Greece, Ireland, Italy, Luxembourg, Netherlands, Portugal, Spain, Sweden and United Kingdom, is 355 million considering 2011 data. This is very similar to the population of the Arab World; i.e. 22 countries. The 27 EU countries consist of the earlier 15 countries beside Bulgaria, Cyprus, Czech Republic, Estonia, Hungary, Latvia, Lithuania, Malta, Poland, Romania, Slovak Republic and Slovenia. The total population of the 27 countries is around 499 million. GCC traffic deaths are compared with those in 15 and $27 \mathrm{EU}$ countries.
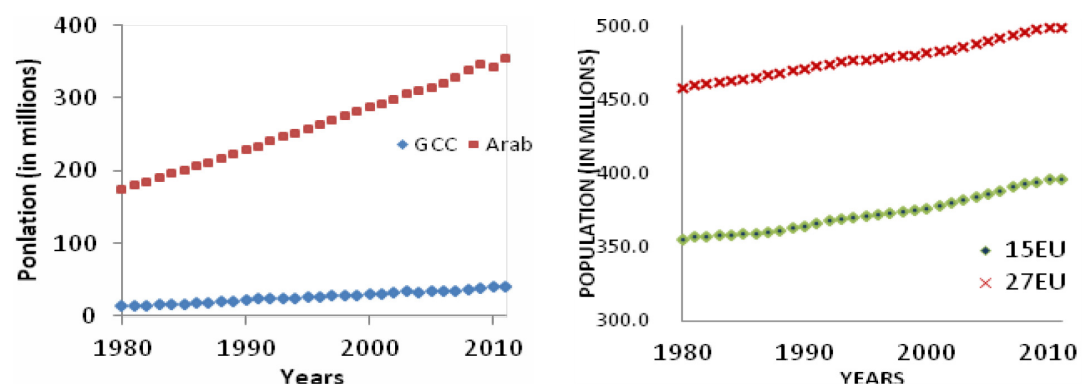

Figure 1: $\quad$ Population trends in GCC, Arab and EU countries (1980-2011).

Similarly, the total vehicle fleet in the GCC countries, as per 2011 statistics, is 15 million and that in the 22 Arab countries is in the range of 48 million. Both are in not comparable with 231 and 278 million vehicles in 15 and $27 \mathrm{EU}$ countries, respectively, as per 2010 statistics (Fig. 2).
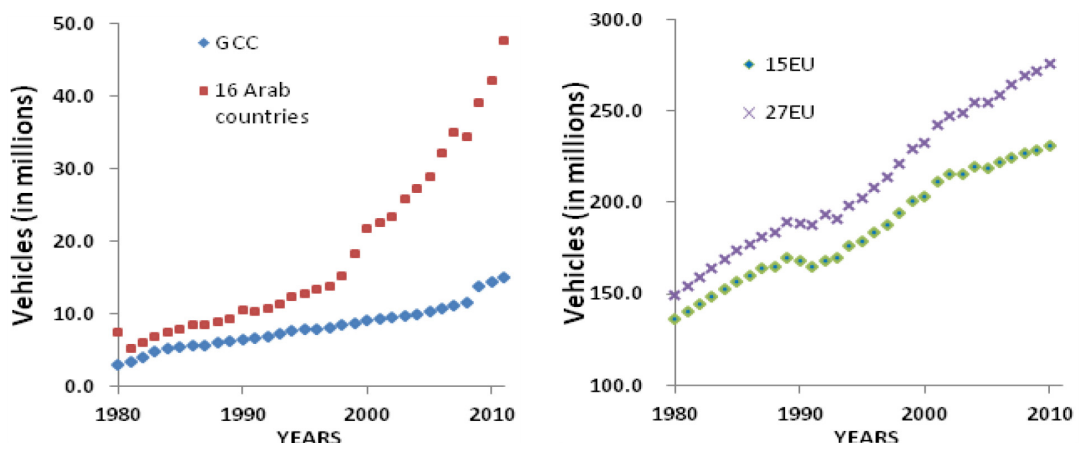

Figure 2: $\quad$ Vehicle fleet in GCC and EU countries (1980-2011). 
The roadways quality in the GCC countries is up to a reasonable standard and is comparable with many European countries. However, enforcement system is yet not well established when compared with the developed countries. The importance of this study lies in the limited traffic safety related literature and scarce historical data related to the GCC countries; especially when compared with developed countries.

\section{Objectives and study approach}

This study aims to analyse the traffic deaths and death rates during the past three decades in the GCC countries and compare them with EU countries. Furthermore, the future trends are also compared.

The population and vehicle data are first gathered along with traffic fatalities for the six GCC countries, namely Saudi Arabia, Kuwait, Qatar, United Arab Emirates, Oman and Bahrain, and for earlier mentioned 15 and 27 EU countries. The data are gathered from the official reports and web sites, well known international data bases and research literature. The GCC data required special attention since the published data, other than population details, are scarce. Therefore, some are obtained through official contacts with the various Traffic Directorates. Death frequencies and rates in the GCC countries for the period from 1980 to $2010 / 11$ along with future predictions are compared with those in the 15 and 27 EU countries using scattered and line diagrams. Future predictions are based on best regression fit. The data from different sources are cross checked, since $80 \mathrm{~s}$ data from past official literature do not always match those published more recently. Ambiguous and contradicting ones, as in the case of sudden change in successive years, are double checked from more than one source.

\section{Data gathering}

The majority of the data are gathered from official publications and several well known data bases like International Road Federation, as IRF World Road Statistics [1], European Union Road Federation, as European Road Statistics [2], Economic Commission for Europe, as Statistics of Road Traffic Accidents in Europe [3], IRTAD, as International Traffic Safety Data and Analysis Group [4], World Health Organization, as the International Status Report on Road Safety Call for Action [5,6] and UK Department of Transport, as Transport Statistics for Great Britain [7]. Several Annual fact books were also used to gather the Data published through official bodies, as General Directorate of Traffic in Bahrain [8], Oman [9] and Dubai [10], Public Security in Saudi Arabia [11] and Ministries of Planning.

Furthermore, the casualty and vehicle data for most of the GCC countries are gathered through official contacts involving Bahrain Directorate of Traffic with various corresponding Directorates. It took 8 months to compile the necessary data together. 
Any missing vehicle or population data points are replaced with interpolated value in case they are between two known values; otherwise they are predicted based on average growth rates. Missing data related to fatalities for Qatar and Kuwait, though being rare, was treated in a similar way. Furthermore, fatality records for countries such as Somalia, Djibouti, Comoros, Sudan, Mauritania, Occupied Palestine, and Libya, though are not part of this study, are enormous. However, the vehicle and death data from these countries, based on most recent data, account for only 9 and 10\%, respectively, from the total 22 Arab countries. The data for Czech and Slovak Republics prior to 1992 are jointly considered since no records are found for each individually during the former Czechoslovakia time. The data for Saudi Arabia are based on the Arabic calendar year which is about 3\% less than the Gregorian year.

\section{Main results}

The trend in the traffic death shows continuous increasing patterns in the various GCC countries (fig. 3). In exception to such trends, that in Bahrain showed somewhat a steady pattern. In 1980 the traffic crash records in Bahrain, Qatar, Kuwait, Oman, UAE and Saudi Arabia showed 70, 143, 140, 379, 372 and 2427 deaths, respectively. These are summed up to 3531 fatalities. Those in 15 and 27 EU countries, considering Czech Republic and Slovak Republic jointly, were 59,879 and 74,876 deaths, respectively. The death records in 2011 in the various GCC countries showed, in respective order, 58, 205, 493, 1056, 720 and 7153 deaths. These sum up to a total of 9685 deaths in the 6 GCC countries; which is about three times those recorded during 1980. Contrary to the GCC countries; the total traffic death in 15 and 27 EU countries showed a substantial drop in 2011 compared with the 1980 records. The total traffic deaths of the $15 \mathrm{EU}$ and 27 EU countries showed, in respective order, 20,764 and 30,170 deaths in 2011; which are about one-third and two-fifth, in respective order, of the 1980 records. While the death records in the various GCC countries, except Bahrain, reached unprecedented peaks in 2011; those in EU countries, as a whole, showed continuous dropping pattern (fig. 4). Such trends in the GCC countries raises serious questions regarding the counteract plans and the effectiveness of the official efforts towards such serious public health problem. The predicted traffic death in the GCC countries, according to the best regression fit (table 1), is expected to reach 10,700 persons by the year 2021. Those in the $15 \mathrm{EU}$ countries, as per polynomial regression model shown in table 1, drop to 10,700 by the same year; which is as much as those for the GCC countries though the population and vehicle fleet in the GCC countries are far lesser than those in the EU countries. The predicted number for $27 \mathrm{EU}$ countries will also continue dropping to 16,000 by the year 2021. Once again, such trends in the GCC countries show serious traffic safety concerns, since the fatality trends in the developing countries show dropping patterns and will continue dropping during the coming decade; but the trends in the GCC countries show continuous increasing pattern. 
Table 1: $\quad$ Best fitted models for traffic deaths for GCC and EU countries.

\begin{tabular}{|c|c|c|c|}
\hline Countries & $\begin{array}{c}\text { Developed models (based on data } \\
\text { from 1970 to 2011) }\end{array}$ & $\mathrm{R}^{2}$ & $\begin{array}{c}\text { Prediction } \\
\text { for Year 2021 }\end{array}$ \\
\hline GCC & 189.33 (year) $-371936^{2}+6647.8($ year) $-5 \mathrm{E}+06$ & 0.93 & 10,700 \\
\hline $15 \mathrm{EU}$ & -1.9686 (year) $^{2}+96$ & 10,700 \\
\hline $27 \mathrm{EU}$ & -15.257 (year $^{2}+59575($ year) $-6 \mathrm{E}+07$ & 0.93 & 16,000 \\
\hline
\end{tabular}

*Kuwait, UAE and Qatar from 1978/80 to 2011.
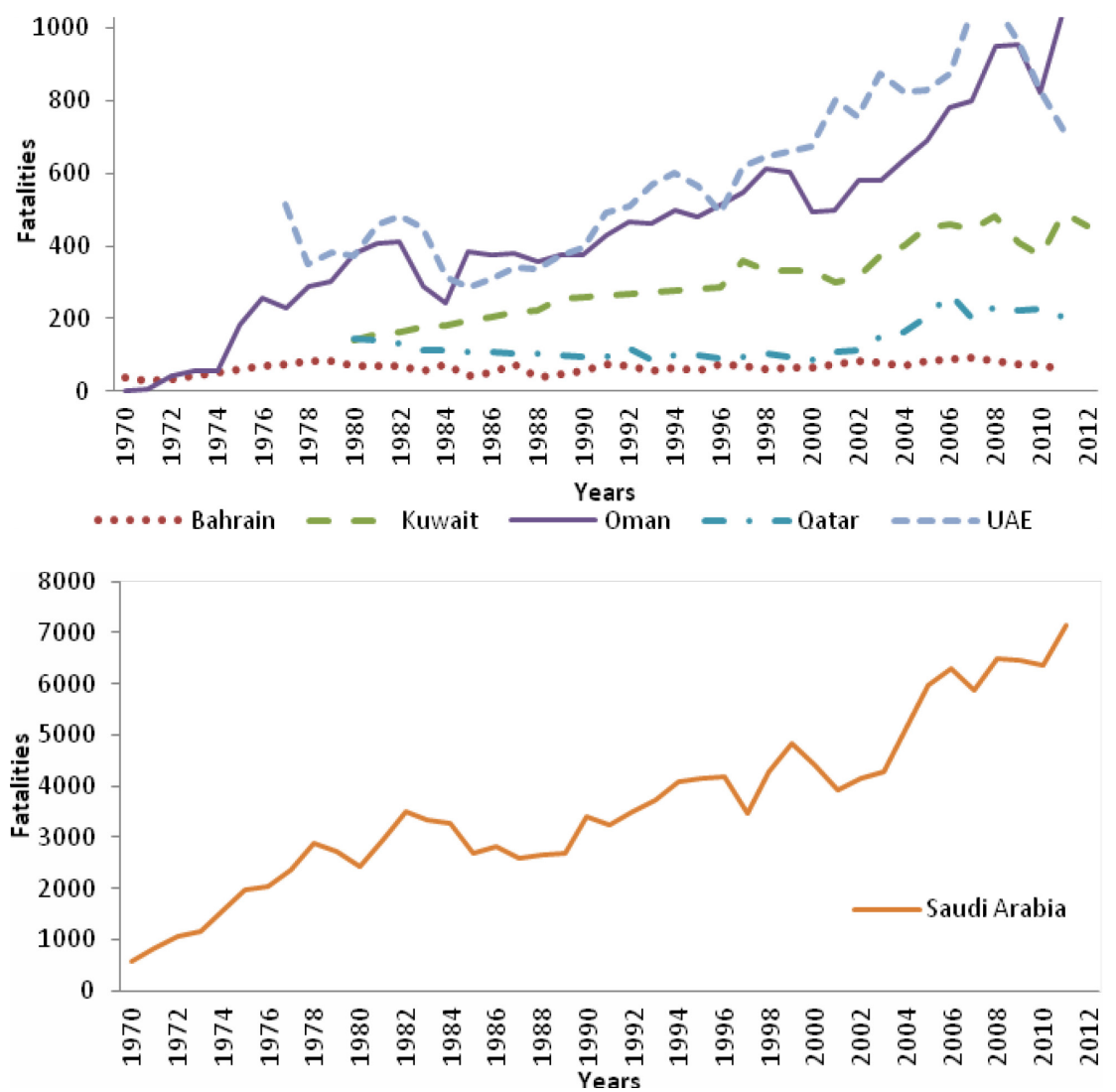

Figure 3: Fatality trend in various GCC countries during the past four decades.

It is worth mentioning that people in the Gulf region are more car-oriented travelers. The average annual growth rate in the vehicle fleet during the past three decades is $5.5 \%$ compared with $1.0 \%$ in 15 EU countries. That in $16 \mathrm{Arab}$ countries is $7.4 \%$ compared with $1.2 \%$ in 27 EU countries. There is, yet, no clear plans to encourage travelers to shift towards safer and more sustainable mode of 
transport, though congestion in major cities is a major concern. In exception to, all the other GCC cities; Dubai (UAE) has succeeded in introducing a successful Mass Transit System (MTS) to its network. MTS is necessary to control users' exposure to accidents by shifting some of the car users towards other safer modes of transport. Murray Mackay [12] considers the latter among the important pillars of Traffic Safety Strategies. Urban planning infrastructure in the GCC countries, though being reasonably of high standards, are not forgiving ones and does not support Traffic Safety Strategies; especially that related to exposure control towards accidents. Another sector requiring intensive improvement is human behavior development, since generally over half of crash fatalities in GCC countries are related to speed, red light crossing and not obeying the rules. It is quite important to mention that while the western drivers comprehend over $74 \%$ of the posted signs; GCC drivers understand only $56 \%$ of them $[13,14]$.

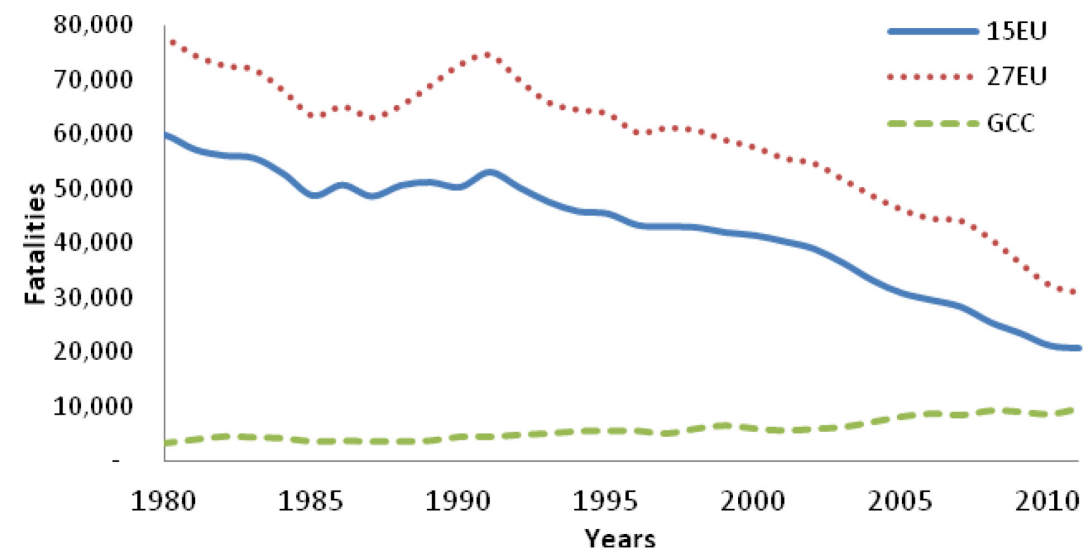

Figure 4: Trend in the traffic deaths in the GCC and EU countries as a whole.

GCC fatality rates per 100,000 population during the past three decades did not show any encouraging trends (fig. 5). The rates during early $80 \mathrm{~s}$ showed the highest values ever recorded. After which, the rates, on average, followed somewhat a constant manner, with lots of varying ups and downs, up to 2011. In general one may observe an average rate of 20 to 25 fatalities per 100,000 inhabitants for Saudi Arabia, Qatar and UAE. That for Bahrain is in the range of 8 to 12 fatalities per 100,000 inhabitants. On the other hand, the rates for Kuwait and Oman showed a pattern which tend to increase, in general, with time. The rates for Oman during early 80s were around 25 fatalities per 100,000 inhabitants and followed a continuous increasing pattern to reach a maximum ever observed of 35 fatalities per 100,000 inhabitants in 2011. Kuwait also followed a similar pattern but with slightly lower rates (fig. 5). It is important to mention that fatality trends in the various GCC countries during the past three decades were far above the international norms. It is also important to mention that the fatality rates during the early $80 \mathrm{~s}$ in several GCC countries tend to be slightly greater 
than what are officially recorded because of unreported death cases in remote areas and villages. Furthermore, the fatality rates per population for the GCC countries as whole showed to be substantially higher than that for the EU countries (fig. 6). While the overall fatality rates for EU countries were in the range of 13 to 14 deaths per 100,000 population during the $80 \mathrm{~s}$; that in the GCC countries proved were in the range of 22 to 27 deaths per 100,000 inhabitants; which is almost twice that for the EU countries. The difference between the GCC and EU reduced during early $90 \mathrm{~s}$. Since then the difference is continuously increasing with time; and is expected to do so, as per developed statistical models shown in fig. 7, during the coming decade if no proper counter action is considered. Currently, the overall rates for the EU countries is in the range of 5 to 6 deaths per 100,000 inhabitants. Those for the GCC countries, as whole, is in the range of 22 to 24 deaths per inhabitants; which is more than four times those for the EU countries. The gap between the two is ever increasing and it is expected to be far greater in a decade's time.
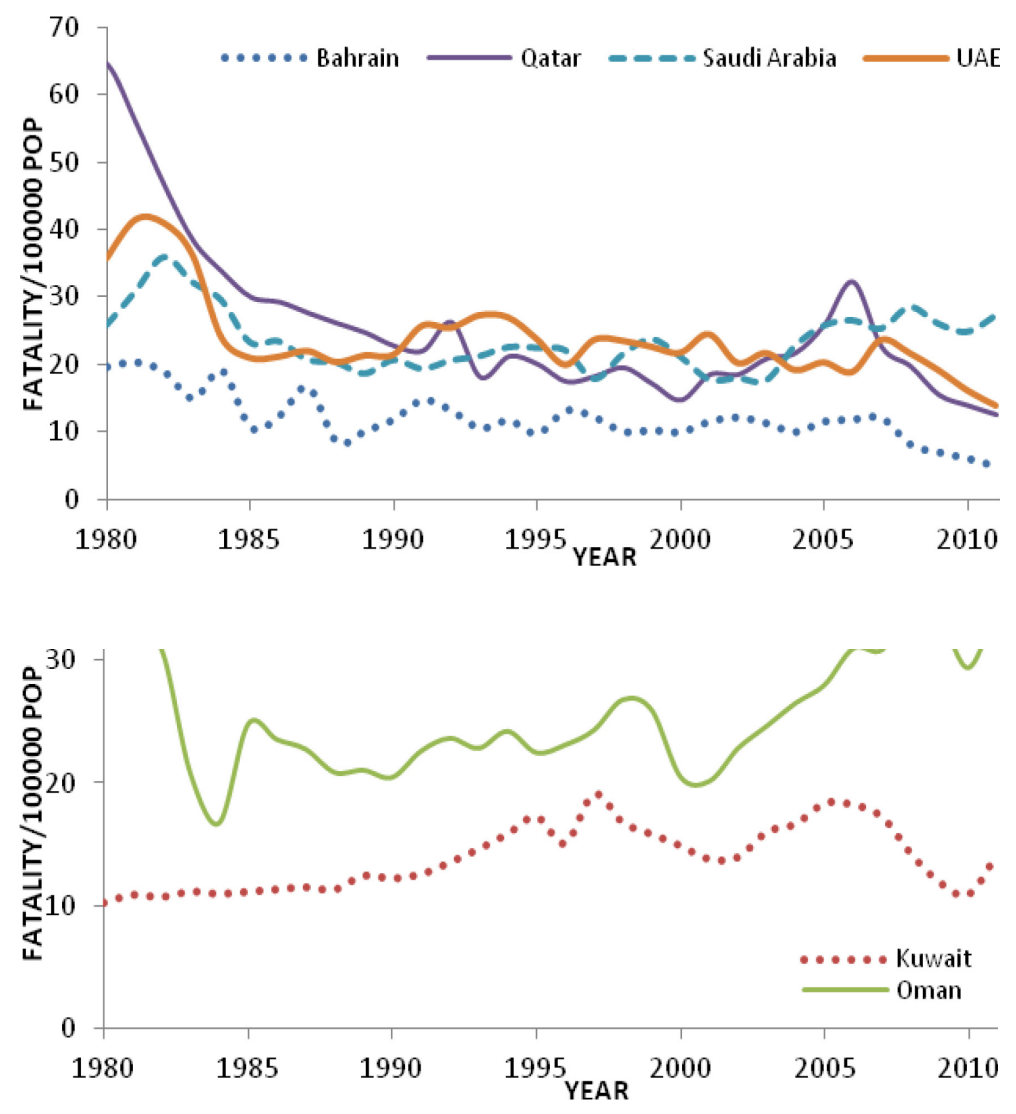

Figure 5: Trend in the traffic deaths rates in various GCC countries (19802011). 


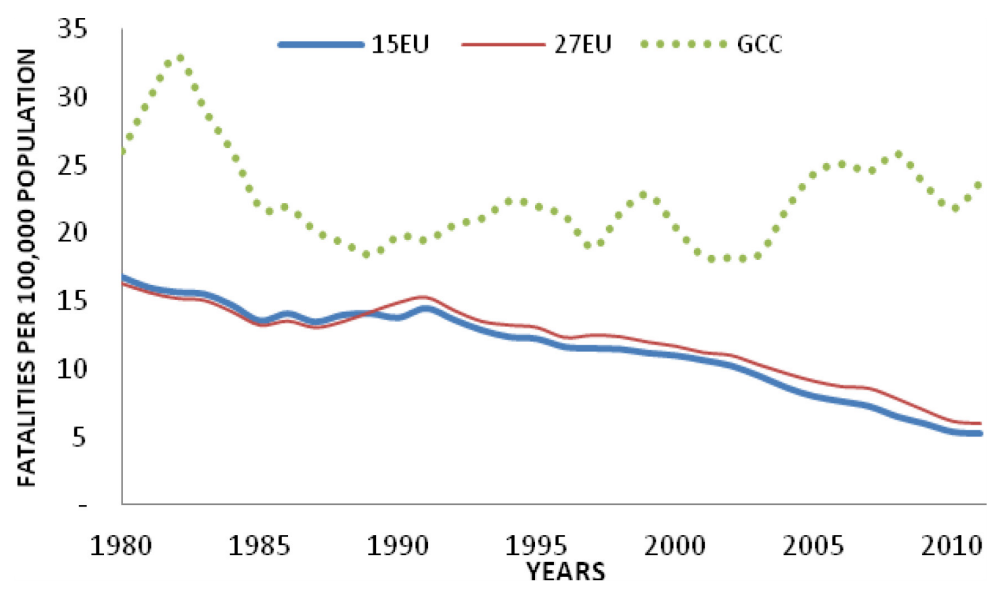

Figure 6: Fatality rated per inhabitants for GCC and EU countries as a whole.

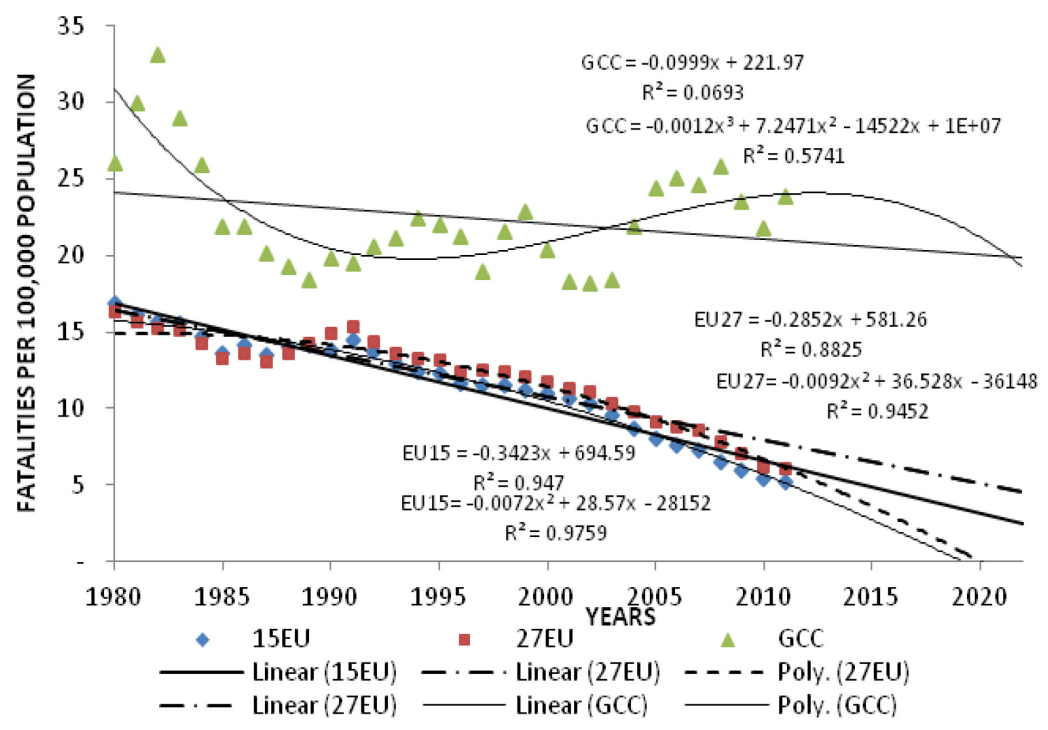

Figure 7: $\quad$ Fitted models to GCC and EU countries.

While quadratic models, with very high $\mathrm{R}^{2}$ values of 0.95 , show that the fatality rates per 100,000 population in EU countries will tend to be close to zero, or at least will be heading towards it, in 10 years time; a linear model for the GCC countries shows that the annual death rate will be in the range of 20 deaths per 100,000 population. However, no model, as can be seen from fig. 7, fits well such scattered fatality rate data for the GCC countries.

In support of the earlier discussion, the fatality rates per 10,000 vehicles for Bahrain, Qatar, Oman and UAE (fig. 8) showed a gentle declining pattern during 
the past 3 decades, with clear varying rates between one year and another. In exception to this, the rates for Saudi Arabia and Kuwait showed slight increasing tendencies. Nevertheless, the rates as can be observed from figs. 8 and 9 for all the GCC countries, in exception of Bahrain, are considerably high compared with EU countries. Such considerable gaps can clearly be observed when the combined GCC rate is compared with combined EU countries shown in Figure 9. The pattern is very similar to that earlier discussed for the fatality rates per 100,000 population. Once again, it is quite interesting to mention that while the rates in the EU countries will be approaching zero, or at least it is heading towards it, in about a decade time, as per developed mathematical models (fig. 10) which are solely data dependent equations; those in the GCC countries will be in the range of 6 deaths per 10,000 vehicles.
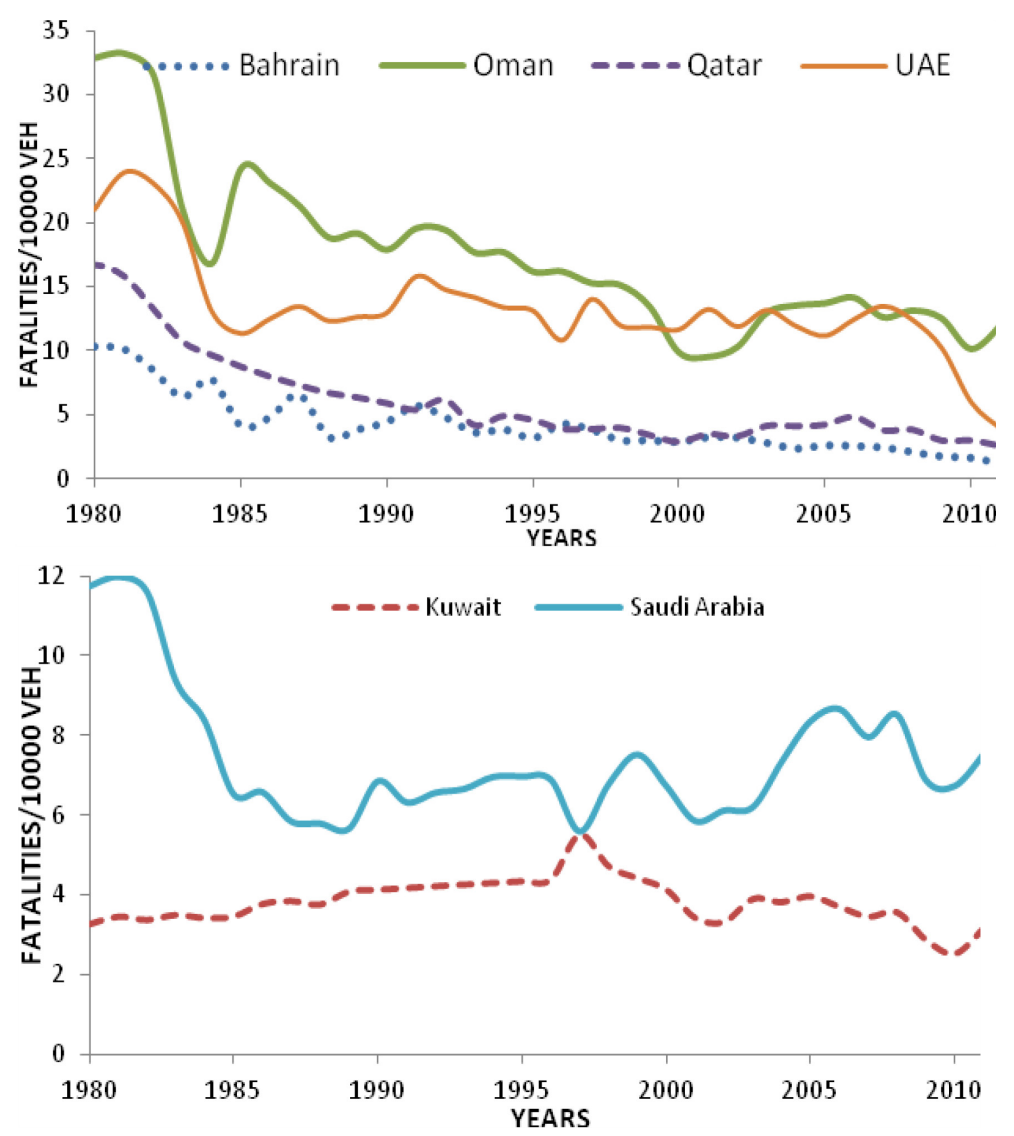

Figure 8: Trend in the traffic deaths per vehicles in various GCC countries. 


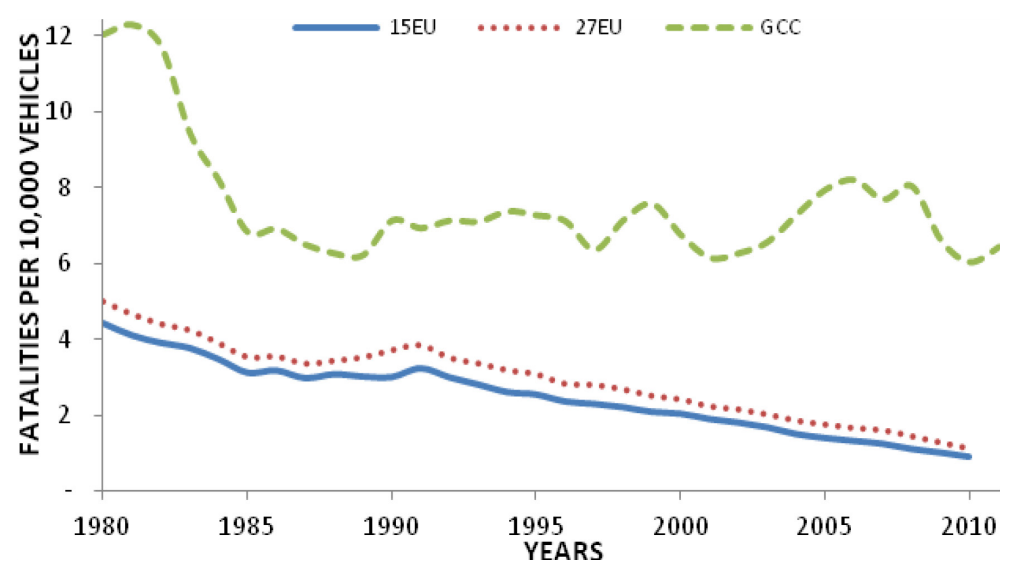

Figure 9: Traffic death trends per vehicles in GCC and EU countries as whole.

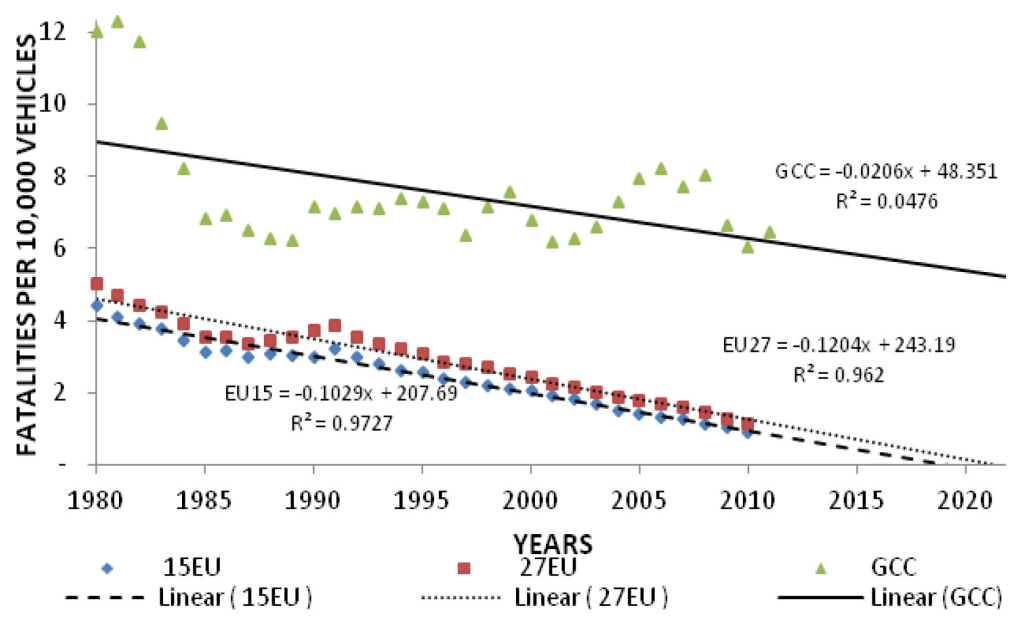

Figure 10: Fitted models to traffic death rates per vehicles for GCC and EU countries.

Once again, such poor safety records require careful reading, proper interpretation of the results and extensive research since there are many contributing factors leading to such high rates of traffic deaths in the GCC. These include, among many others, lack of measurable long term traffic safety plans, inconsistent handling of traffic safety strategies, poor involvement of Non Governmental Organization (NGO) in traffic safety problem, poor coordination between various stake holders, poor research involvement in the traffic safety crises and limited post accident rehabilitation centres. Mentioning the earlier 
weaknesses does not mean exclusion of successful programs. For example, Riyadh, capital of Saudi Arabia, Dubai, in UAE, and Bahrain has put a lot of effort, especially in human behaviour and enforcements, to reduce traffic fatalities.

Most of the EU countries sat long term national plans since the $70 \mathrm{~s}$ and $80 \mathrm{~s}$ for the traffic casualty reduction. In 1987 a target was sat in UK, for example, to reduce road casualties by one-third by 2000 . As a result, road death has fallen by $39 \%$ [15]. There are many other similar successful stories throughout the $15 \mathrm{EU}$ countries to improve the current plans and follow them up. There are great opportunities to transfer such experience to the GCC countries through the various involved bodies as consulting offices, research institutions and contractors. Some, as TRL and Sewe Road, are already involved in developing traffic safety plans and procedures for casualty reductions in the region. Manufacturers may also involve better vehicle high-tech to suite the regional problems. Supporting traffic safety through ITS and administering the traffic more efficiently are also sectors requiring further investigation in the region.

\section{Conclusions and recommendations}

Over three decades traffic death records, frequencies and rates along with vehicle fleets are presented here for the first time for the GCC countries, involving Saudi Arabia, Kuwait, Qatar, Oman, United Arab Emirates and Bahrain. Traffic crash records summed up to 3531 fatalities in the GCC countries during 1980. Those in 15 and $27 \mathrm{EU}$ countries were 59,879 and 74,876 deaths, respectively. The death records reached 9685 deaths in the 6 GCC countries; which are about three times those recorded during 1980. Contrary to this; traffic death in EU countries showed a substantial continuous drop with the time. The total traffic deaths of the $15 \mathrm{EU}$ and $27 \mathrm{EU}$ countries showed, in respective order, 20,764 and 30,170 deaths in 2011; which are about one-third and two-fifth, in respective order, of the 1980 records. The trends in fatality in the various GCC countries were far above the international norms during the past three decades. The gap in the fatality rates between GCC and EU countries are continuously increasing with time; and are expected to do so during the coming decade unless proper counter actions are considered. Such poor safety records require careful reading, proper interpretation of the results and extensive research since there are many contributing factors leading to such high rates in traffic deaths. These include, among many others, lack of measurable long term traffic safety plans, inconsistent handling of traffic safety strategies, poor involvement of Non Governmental Organization in traffic safety problem, poor coordination between various stake holders, poor research involvement. Furthermore, transport users in the Gulf region are more car-oriented travelers. Other modes of transport are necessary to encourage travelers to shift towards safer and more sustainable modes of transport. Urban planning infrastructure, despite being of reasonably high standards, requires careful revision to become more forgiving for the road users so as to support Traffic Safety Strategies. Development human behavior is also necessary. 


\section{References}

[1] International Road Federation "IRF World Road Statistics", Geneva Programme Centre, Switzerland, Series 2004 to 2010.

[2] European Union Road Federation " European Road Statistics 2008", The Voice of the European Road, series from 2008 to 2010.

[3] Economic Commission for Europe "Statistics of Road Traffic Accidents in Europe 1994”, UN, Geneva, series 1991, 1994, 1995.

[4] Organization for Economic Co-Operation and Development "International Traffic Safety Data and Analysis Group", 2008. www.cemt.org/irtad /IRTADPUBLIC/weng1.html (as on Nov 2010).

[5] World Health Organization "International Status Report on Road Safety Call for Action", Regional office for the Eastern Mediterranean, 2010. www.who.int/violence_injury_prevention/road_safety_status_2009

[6] World Health Organization "Eastern Mediterranean Status Report on Road Safety Call for Action", Regional office for the Eastern Mediterranean, 2010.

[7] The Department of Transport "Transport Statistics great Britain Casualty Report" a Publication of the Government Statistics Service, HMSO, London, UK, series 1992 to 2007.

[8] General Directorate of Traffic "Traffic Accident Facts in Kingdom of Bahrain", Ministry of Interior, Bahrain series 1970 to 2011.

[9] Directorate General of Traffic 'Facts and Figures 2012" Royal Oman Police, Oman, 2012.

[10] General Traffic Department "Traffic Accident Facts in Dubai", Ministry of Interior, Dubai, UAE, 2003. www.dubaipolice.gov.ae/portal/downloads/ ACCIDENTFACTS2003.pdf

[11] General Directorate of Traffic “Annual Statistical Report”, Department of Traffic Studies, Public Security, Ministry of Interior, Riyadh, Saudi Arabia, 2006.

[12] Mackay, M "Reducing Traffic Injury: a Global Challenge" Safety on Road: an International Conference (SORIC' 98), University of Bahrain, pp. 397400, Bahrain 1998.

[13] Hashim M. N. Al-Madani, Abdul Rahman Al-Janahi "Role of Drivers' Personal Characteristics in Understanding Traffic Sign Symbols", Accident Analysis and Prevention, 34, 185-196, USA, 2001.

[14] H. M. N. Al-Madani, A-R Al-Janahi "Assessment of Drivers' Comprehension of Traffic Signs based on their Traffic, Personal and Social Characteristics", Transportation Research: F, Traffic Psychology \& Behaviour, 5, 361- 374, USA, 2002.

[15] Department of the Environmental, Transport and the regions "Tomorrow's Roads: Safer for Everyone, The Government's Road Safety Strategy and Casualty Reduction Targets for 2010”, Wetherby, UK, 2000. 